\title{
FORMAÇÃO DE MUDAS DE RÚCULA EM FUNÇÃO DO TIPO DE BANDEJA E DO SUBSTRATO ALTERNATIVO
}

Silvana Ramlow Otto Teixeira da Luz ${ }^{1}$, Jhonny Kelvin Dias Martins ${ }^{1}$, Josiane Fernandes Keffer ${ }^{2}$, Bruna Firmino Enck ${ }^{1}$, Paula Caroline Machado ${ }^{1}$

${ }^{1}$ Graduado (a) do curso de Agronomia, Fundação Universidade Federal de Rondônia - UNIR, (silvanaotto2016@gmail.com) Rolim de Moura-Brasil.

${ }^{2}$ Mestranda em Ciências Ambientais, Universidade Federal de Mato Grosso UFMT, Sinop-MT, Brasil.

Recebido em: 06/04/2018 - Aprovado em: 10/06/2018 - Publicado em: 20/06/2018 DOI: 10.18677/EnciBio_2018A51

\begin{abstract}
RESUMO
A rúcula é uma das hortaliças mais apreciadas na forma de saladas. O sucesso do cultivo da rúcula inicia com a produção de mudas de qualidade. Entre os fatores que influenciam a qualidade das mudas, a escolha do substrato e o tamanho das células das bandejas utilizadas são os mais importantes. Diante disso, o objetivo deste trabalho foi avaliar a formação de mudas de rúcula utilizando-se dois tipos de substratos e bandejas com diferentes tamanhos de células. O experimento foi conduzido na fazenda experimental da Fundação Universidade Federal de Rondônia no mês de novembro de 2017. O delineamento experimental utilizado foi em blocos casualizados, em esquema fatorial $2 \times 2$ com quatro repetições. O primeiro fator consistiu de dois tipos de bandejas de poliestireno expandido, sendo uma de 200 e outra de 288 células. O segundo fator foi composto por dois tipos de substratos, sendo eles Fibra de Coco (FC) e Substrato Comercial Plantmax® Hortaliças (SC). Foram avaliadas a altura da planta (AP), número de folhas (NF), massa fresca da parte aérea (MFPA) e comprimento da raiz (CR). De acordo com os resultados obtidos, o substrato comercial foi superior a fibra de coco para as variáveis: altura de planta e massa fresca da parte aérea. Com relação ao tamanho das células, as bandejas de 200 células apresentaram desempenho superior das mudas.
\end{abstract}

PALAVRAS-CHAVE: Euruca sativa L., produção de mudas, tamanho das células da bandeja.

\section{STRUCTURE OF RUCCHES WITH SUBSTRATE AND TYPE OF TRAY}

\begin{abstract}
Arugula is one of the most prized vegetables in the form of salads. The success of arugula cultivation begins with the production of quality seedlings. Among the factors that influence seedling quality, the choice of substrate and the cell size of trays used are the most important. Therefore, the objective of this work was to evaluate the formation of rocket seedlings using two types of substrates and trays with different cell sizes. The experiment was conducted in the experimental farm of the Federal
\end{abstract}


University of Rondônia Foundation in November, 2017. The experimental design was a randomized complete block design in a $2 \times 2$ factorial scheme with four replications. The first factor consisted of two types of expanded polystyrene trays, one of 200 and one of 288 cells. The second factor was composed of two types of substrates, being Coco Fiber (CF) and Commercial Substrate Plantmax ${ }^{\circledR}$ Hortaliças (SC). Plant height (AP), number of leaves (NF), fresh shoot mass (MFPA) and root length (CR) were evaluated. According to the results, the commercial substrate was superior to coconut fiber for the variables plant height and fresh shoot mass. Regarding the cell size, the trays of 200 cells presented superior performance of the seedlings.

KEYWORDS: Euruca sativa L., seedling production, tray cell size.

\section{INTRODUÇÃO}

A rúcula (Euruca sativa L.) é uma hortaliça da família Brassicaceae, muito apreciada na alimentação humana principalmente na forma de saladas e em pizzas, é bastante nutritiva, rica em minerais como potássio, enxofre e ferro, além das vitaminas A e C (Porto et al., 2013; Ferreira et al., 2017). O sucesso do cultivo de hortaliças depende de cuidados que vão desde a produção de mudas até a póscolheita (COSTA et al., 2010). A etapa de produção de mudas é uma das mais importantes no cultivo de hortaliças, pois influencia diretamente no resultado final do produto (LUQUI et al., 2015), pois mudas debilitadas comprometem o desenvolvimento da cultura e acarreta em perdas na produção (ECHER et al., 2007).

Entre os fatores que estão diretamente relacionados à qualidade das mudas, a escolha do substrato a ser utilizado é um dos mais importantes (MEDEIROS et al., 2016). As funções do substrato são de sustentar a planta, fornecer nutrientes e permitir as trocas gasosas no sistema (WATTHIER et al., 2016), além de proporcionar sucesso na germinação e adequado desenvolvimento às mudas (MINAMI ; SALVADOR, 2010). Segundo Souza et al. (2014) o substrato ideal deve reunir características físicas e químicas que promovam a retenção de umidade e disponibilidade de nutrientes, de modo que atenda às necessidades da plântula.

Além da escolha do substrato, para a produção de mudas de qualidade devese considerar o método de produção dessas. Segundo Vogel et al. (2016), a semeadura da rúcula pode ser realizada diretamente no canteiro definitivo ou em bandejas para o posterior transplantio. Entretanto, a produção de mudas em bandejas proporciona diversas vantagens em relação a semeadura em local definitivo como, uniformidade das mudas, colheitas mais precoces, além de redução de custos com espaços físicos e tratamentos de pragas (MEDEIROS et al., 2008). Além disso, os recipientes protegem as raízes dos danos mecânicos e da dissecação, promovendo a sobrevivência no local definitivo (SILVA;QUEIROZ, 2014).

Outro fator a ser considerado na produção de mudas em bandejas é o tamanho das células, pois isso interfere diretamente na qualidade das mudas (LATIMER, 1991). Segundo Echer et al. (2007), a utilização de bandejas com células de menor volume pode proporcionar despendimento insuficiente das mudas, reduzindo a qualidade do produto final. Em contrapartida, segundo os mesmos autores, em bandejas com células de maior volume a produção de mudas por área é menor e o custo com substrato é elevado. Dessa forma, é imprescindível cultivar as mudas em recipientes de tamanho adequado ao seu desenvolvimento e que não acarretem prejuízos ao produtor. 
Diante do exposto, objetivou-se com este trabalho avaliar a formação de mudas de rúcula utilizando-se os substratos fibra de coco e substrato comercial Plantmax ${ }^{\circledR}$ Hortaliças e bandejas de 200 e 288 células.

\section{MATERIAL E MÉTODOS}

O experimento foi realizado em novembro de 2017, em casa de vegetação no Campus experimental da Universidade Federal de Rondônia (UNIR), localizado no município de Rolim de Moura RO. O clima da região é tropical quente e úmido com estações de seca bem definidas (junho a setembro), com chuvas intensas nos meses de novembro a março. A precipitação média anual é de $2.250 \mathrm{~mm}$, a umidade relativa do ar é elevada no período chuvoso, em torno de $85 \%$ e as temperaturas médias mínimas são de $24^{\circ} \mathrm{C}$ e as máximas de $32^{\circ} \mathrm{C}$ (SEDAM, 2016).

$O$ delineamento experimental utilizado foi em blocos casualizados, em esquema fatorial $2 \times 2 \mathrm{com}$ quatro repetições. $O$ primeiro fator consistiu de dois tipos de bandejas de poliestireno expandido, sendo uma de 200 e a outra de 288 células, com volumes de $16 \mathrm{~cm}^{3}$ e $12 \mathrm{~cm}^{3}$ respectivamente. $O$ segundo fator foi composto por dois tipos de substratos, sendo eles Fibra de Coco (FC) e Substrato Comercial Plantmax® Hortaliças (SC).

A semeadura foi realizada de forma manual no dia 01/11/2017, colocando-se duas sementes da cultivar de rúcula Selecta por célula, permitindo-se o desenvolvimento de apenas uma plântula por célula ao longo do período. As bandejas permaneceram em casa de vegetação até o momento da avaliação das mudas. Os tratos culturais realizados foram a irrigação (diariamente) e o desbaste realizado aos 10 dias da emergência das plântulas.

Aos 25 dias após a semeadura retirou-se, ao acaso, dez plântulas dentro de cada unidade experimental para avaliar os seguintes parâmetros: número de folhas (NF), contado visualmente; altura da planta (AP), determinada com régua graduada, medindo-se a distância entre o colo e o ápice da planta; comprimento de raiz (CR), determinado também com o auxílio de régua graduada, medindo-se a distância do colo da planta até a extremidade da raiz principal; massas frescas da parte aérea (MFPA) e das raízes (MFR), obtidas por meio da pesagem de dez plântulas em balança digital de precisão.

Os dados foram submetidos à análise de variância (ANOVA) e as médias foram comparadas pelo teste de Tukey ao nível de $5 \%$ de probabilidade de erro por meio do programa ASSISTAT versão 7.7.

\section{RESULTADOS E DISCUSSÃO}

A análise de variância indicou diferença significativa para os fatores substrato e tamanho de células, para os parâmetros avaliados. Quanto à interação entre os fatores, esta foi significativa somente para a variável massa fresca da parte aérea (MFPA) (Tabela 1).

TABELA 1. Resumo da análise de variância para as variáveis: Altura da planta (AP), Número de folhas (NF), Comprimento da raiz (CR), Massa fresca da parte aérea (MFPA) e Massa fresca da raiz (MFR).

\begin{tabular}{lcccccc}
\hline \multicolumn{1}{c}{$\begin{array}{c}\text { Fontes de } \\
\text { Variação }\end{array}$} & \multirow{2}{*}{$\mathrm{GL}$} & \multicolumn{5}{c}{ Quadrados Médios } \\
\cline { 3 - 7 } & & $\mathrm{AP}$ & $\mathrm{NF}$ & $\mathrm{CR}$ & $\mathrm{MFPA}$ & $\mathrm{MFR}$ \\
\hline Substrato $(\mathrm{S})$ & 1 & $2,46^{\text {ns }}$ & $15,00^{* *}$ & $1,84^{\text {ns }}$ & $23,22^{* *}$ & $1,93^{\text {ns }}$ \\
Bandeja $(\mathrm{B})$ & 1 & $61,53^{* *}$ & $29,40^{* *}$ & $0,91^{\text {ns }}$ & $77,91^{* *}$ & $18,29^{* *}$
\end{tabular}




\begin{tabular}{|c|c|c|c|c|c|c|}
\hline Interação (S x B) & 1 & $1,38^{\text {ns }}$ & $0,60^{\text {ns }}$ & $1,11^{\mathrm{ns}}$ & $4,92^{*}$ & $0,60^{\mathrm{ns}}$ \\
\hline Resíduo (D) & 12 & 0,06 & 0,10 & 0,24 & 0,0021 & 0,089 \\
\hline
\end{tabular}

De acordo com os dados apresentados na tabela 2, observou-se que a utilização do substrato comercial resultou em mudas com maior número de folhas (NF) $(4,12)$ e massa fresca da parte aérea (MFPA) $(0,52 \mathrm{~g})$, quando comparado com as mudas produzidas com o substrato de fibra de coco. Para as demais variáveis não houve diferença significativa das mudas de rúcula em ambos os substratos.

Cunha et al. (2014) avaliando a formação de mudas de alface cv. Vera em bandejas com diferentes substratos, observaram maior valor de massa fresca da parte aérea no substrato comercial, alcançando 0,997 g. Já Ferreira et al. (2017) avaliaram a qualidade das mudas de rúcula em função de condicionadores de substratos e observaram que a utilização de casca de coco proporcionou um aumento de $20,3 \%$ na massa seca da parte aérea em relação a testemunha (substrato comercial).

Com relação aos tipos de bandejas, observou-se que a bandeja de 200 células, apresentou desempenho superior para as variáveis altura de planta $(3,87$ $\mathrm{cm})$, número de folhas $(4,25)$, massa fresca da parte aérea $(0,57 \mathrm{gg})$ e massa fresca observaram maior valor de massa fresca da raiz $(2,52 \mathrm{~g})$. Isso provavelmente se deve ao fato de as bandejas de 200 células apresentam maior capacidade de volume de substrato, proporcionando assim um ambiente favorável para o desenvolvimento das mudas.

Ao avaliarem o desempenho de mudas de melancia em bandejas de tamanhos de células diferentes Dalastra et al. (2016), concluíram que o tamanho das células das bandejas influenciou na formação das plântulas, sendo que a bandeja de 72 células foi a melhor opção para a formação de mudas dessa espécie. Echer et al. (2007) avaliaram o desempenho de mudas de beterraba em bandejas de 128 e 200 células e, concluíram que as mudas produzidas em bandejas de 128 células apresentaram desempenho superior para as variáveis: massa seca de raízes, altura de planta e comprimento do sistema radicular.

TABELA 2. Altura de Planta (AP), Número de Folhas (NF), Comprimento da Raiz (CR), Massa Fresca da Parte Aérea (MFPA) e Massa Fresca da Raiz (MFR) de mudas de rúcula produzidas em dois tipos de substratos e bandejas.

\begin{tabular}{cccccc}
\hline Substrato & $\mathrm{AP}(\mathrm{cm})$ & $\mathrm{NF}$ & $\mathrm{CR}(\mathrm{cm})$ & MFPA $(\mathrm{g})$ & MFR $(\mathrm{g})$ \\
\hline Fibra de coco & $3,27 \mathrm{~A}$ & $3,50 \mathrm{~B}$ & $4,95 \mathrm{~A}$ & $0,41 \mathrm{~B}$ & $2,10 \mathrm{~A}$ \\
Substrato Comercial & $3,47 \mathrm{~A}$ & $4,12 \mathrm{~A}$ & $5,28 \mathrm{~A}$ & $0,52 \mathrm{~A}$ & $2,31 \mathrm{~A}$ \\
\hline Bandejas & $\mathrm{AP}(\mathrm{cm})$ & $\mathrm{NF}$ & $\mathrm{CR}(\mathrm{cm})$ & MFPA $(\mathrm{g})$ & MFR $(\mathrm{g})$ \\
\hline 200 células & $3,87 \mathrm{a}$ & $4,25 \mathrm{a}$ & $5,23 \mathrm{a}$ & $0,57 \mathrm{a}$ & $2,52 \mathrm{a}$ \\
288 células & $2,87 \mathrm{~b}$ & $3,37 \mathrm{~b}$ & $5,00 \mathrm{a}$ & $0,37 \mathrm{~b}$ & $1,88 \mathrm{~b}$ \\
\hline CV $\%$ & 7,55 & 8,47 & 9,30 & 9,78 & 13,58 \\
\hline
\end{tabular}

1Médias seguidas pela mesma letra, maiúscula para comparação entre substratos e 2minúscula para a comparação entre bandejas, não diferem estatisticamente entre si pelo teste de Tukey $(P<0,05)$.

$\mathrm{Na}$ tabela 3 são apresentados: o efeito da interação entre os tipos de substratos e o tamanho das células das bandejas para a variável MFPA. Observouse que o substrato comercial apresentou mudas com maior MFPA na bandeja de 200 células $(0,6550 \mathrm{~g})$. Com relação ao volume do recipiente, a bandeja de 200 células se mostrou superior para ambos os substratos avaliados. Isso ocorreu devido à capacidade de acondicionar maior volume de substrato nesse tipo de ENCICLOPÉDIA BIOSFERA, Centro Científico Conhecer - Goiânia, v.15 n.27; p. $44 \quad 2018$ 
bandeja, o que proporciona melhores condições para o desenvolvimento das plântulas. Segundo Echer et al. (2007), em células de menor volume o espaço físico e a quantidade de substrato pode ser insuficiente para o desenvolvimento adequado das mudas, além de impossibilitar que as cultivares expressem todo o seu potencial genético.

TABELA 3. Massa Fresca da Parte Aérea (MFPA) de mudas de rúcula em função dos diferentes substratos e bandejas.

\begin{tabular}{lll}
\hline \multirow{2}{*}{ Substrato } & \multicolumn{2}{c}{ MFPA $(\mathrm{g})$} \\
\cline { 2 - 3 } & \multicolumn{2}{c}{ Bandeja } \\
\cline { 2 - 3 } & 200 células & 288 células \\
\hline Fibra de Coco & $0,4925 \mathrm{bA}$ & $0,3400 \mathrm{aB}$ \\
Substrato Comercial & $0,6550 \mathrm{aA}$ & $0,4000 \mathrm{aB}$ \\
\hline CV\% & \multicolumn{2}{c}{9,78} \\
\hline *Médias seguidas da mesma letra, maiúscula na linha e minúscula na \\
coluna, não diferem entre si pelo teste de Tukey $(\mathrm{P}<0,05)$.
\end{tabular}

Marques et al. (2003) avaliaram a qualidade das mudas de alface formadas em bandejas com 128, 200 e 288 células e, concluíram que as maiores médias sempre ocorreram nas mudas provenientes de bandejas com maior volume de substrato, sendo que as piores mudas foram obtidas nas bandejas com 288 células. Da mesma forma, Ferreira et al. (2014) avaliaram a produção de mudas de almeirão em bandejas de 128, 200 e 288 células e também constataram que bandejas com menor número de células propiciaram a melhor formação de mudas de almeirão.

\section{CONCLUSÃO}

O substrato comercial e a bandeja de 200 células proporcionaram melhor desenvolvimento para todas as variáveis de crescimento de rúcula analisadas.

\section{AGRADECIMENTOS}

Os autores agradecem a Fundação Universidade Federal de Rondônia por ceder a área experimental para a realização do experimento.

\section{REFERÊNCIAS}

COSTA, E.; LEAL, P. A. M.; GOMES, V. do A.; MACHADO, D.; JARA, M. C. de S. Biomassa de mudas de pepinos híbridos conduzidos sob ambientes protegidos. Bragantia, Campinas, v.69, n.2, p.381-386, 2010. DOI: 10.1590/S000687052010000200017.

CUNHA, C.; GALLO, A. S.; GUIMARÃES, N. F.; SILVA, R. F. Substratos alternativos para produção de mudas de alface e couve em sistema orgânico. Scientia Plena, Vol. 10, Num. 11, 2014. Disponível em: https://www.scientiaplena.org.br/sp/article/view/2040/1073.

DALASTRA, G. M.; ECHER, M. M.; HACHMANN, T. L.; GUIMARÃES, V. F.; SCHMIDT, M. H.; CORBARI, F. L. Desenvolvimento e produtividade da melancia em 
função do método de cultivo. Revista de Agricultura, Piracicaba, v. 91, p. 54-66, 2016.

ECHER, M. M.; GUIMARÃES, V. F.; ARANDA, A. N.; BORTOLAZZO, E. D.; BRAGA, J. S. Avaliação de mudas de beterraba em função do substrato e do tipo de bandeja. Semina Ciências Agrárias, Londrina, v. 28, n. 1, p. 45-50, 2007. DOI: 10.5433/1679-0359.2007v28n1p45.

FERREIRA, L. G.; PRZENDZIUK, G. B.; MONDIN, M. NESSI JUNIOR, P. Bandejas e substratos na produção de mudas de almeirão. Revista Enciclopédia Biosfera, Centro Científico Conhecer - Goiânia, v.10, n.19; p. 400, 2014.

FERREIRA, R. L. F.; ARAÚJO NETO, S. E.; ALVES, G. K. E. B.; SIMÕES, A. C.; BOLDT, R. H. Qualidade de mudas e produtividade de rúcula em função de condicionadores de substratos. Revista Agropecuária Científica no Semiárido. v. 13, n. 3, 2017. Disponível em: http://revistas.ufcg.edu.br/acsa/index.php/ACSA/index.

LATIMER, J. G. Container size and shape influence growth and landscape performance of marigold seedling. HortScience, Alexandria, v.26, n.2, p.124-126, 1991.

LUQUI, L. L.; COSTA, E.; ALVES, A. C.; BINOTTI, F. F. S.; CARDOSO, E. D. Mudas de cultivares de pepineiro em diferentes substratos. Revista de Agricultura Neotropical, Cassilândia-MS, v. 2, n. 1, p. 1-9, jan./mar. 2015. Disponível em: http://periodicosonline.uems.br/index.php/agrineo/article/view/252.

MARQUES, P.A.A.; BALDOTTO, P.V.; SANTOS, A.C.P.; OLIVEIRA, L. Qualidade de mudas de alface formadas em bandejas de isopor com diferentes números de células. Horticultura Brasileira, Brasília, v. 21, n. 4, p. 649-651, outubro-dezembro 2003. DOI: 10.1590/S0102-05362003000400015.

MEDEIROS, E. V. de; SERAFIM, E. C. da S; GRANGEIRO, L. C., SOBRINHO,J, E; NEGREIROS, M. Z.de; SALES JÚNIOR, R. Influência do agrotextil sobre a densidade populacional de Monosporascus cannonballus em solo cultivado com melancia (Citrullus lanatus). Ciência agrotecnologia, Lavras, v. 32, n. 3, p. 797-803, 2008. DOI: 10.1590/S1413-70542008000300014.

MEDEIROS, C. H.; CUSTÓDIO, T.; RIBEIRO, L. V.; SEDREZ, F.; MORSELLI, T. B. G. A. Substratos alternativos para a produção de mudas de alface. Revista Cientifica Rural-Urcamp, Bagé-RS, vol. 18, n.1, 2016.

MINAMI, K. \& SALVADOR, E. D. Substrato para mudas. Piracicaba: Degaspari, 2010.

PORTO, R. A.; BONFIM, E. M.; SOUZA, D. S. M.; CORDOVA, N. R. M.; POLYZEL, A. C.; SILVA, T. J. A. Adubação potássica em plantas de rúcula: produção e eficiência no uso da água. Revista agroambiente, Boa Vista, v. 7, n. 1, p. 28-35, 2013. 
SEDAM - Secretaria do Estado do Desenvolvimento Ambiental e GOGEO Coordenadoria de Geociências. Boletim climatológico de Rondônia ano 2016. Porto Velho, v.12, 2016. Disponivel em: http://sedamro.wix.com/sedam_ro_focosqueimada\#!qualidade-do-ar. Acessado em 10 de janeiro de 2018.

SILVA, E. C. \& QUEIROZ, R. L. Formação de mudas de alface em bandejas preenchidas com diferentes substratos. Bioscience Journal, Uberlândia, v. 30, n. 3, p. 725-729, May/June, 2014.

SOUZA, F. C. A.; SOUZA, J. A. M.; PIRES, E. S.; CORDEIRO, R. A. M.; ALVES, J. D. N. Produção de mudas de quiabeiro em estufa com diferentes substratos orgânicos. Nucleus, v.11, n.1, abr. 2014. DOI: 10.3738/1982.2278.1051.

VOGEL, G. F.; MARTINKOSKI, L.; MAGGI, C. F. Eficiência de sementes agroecológicas de rúcula (Eruca sativa L.) em diferentes tamanhos de bandeja. Revista Cultivando o Saber. Volume 9 - n ${ }^{\circ}$, p. 84 - 92. Janeiro a Março de 2016.

WATTHIER, M.; SILVA, M. A. S.; SCHWENGBER, J. E.; FONSECA, F. D.; NORMBERG, A. Produção de mudas e cultivo a campo de beterraba em sistema orgânico de produção. Revista Brasileira de Agropecuária Sustentável (RBAS), v.6, n.2, p.51-57, Junho, 2016. Disponível em: http://www.rbas.com.br/index.php/rbas/article/view/328. 